\title{
A NUMERICAL ANALYSIS FOR SOME NON-LINEAR CONSTITUTIVE PROBLEMS IN SOLID MECHANICS
}

\author{
NGO HuONG NHU \\ Institute of Mechanics
}

\begin{abstract}
The paper deals with the application FEM for solving nonlinear constitutive problems in solid mechanics. The basis equations and algorithms of iterative processing are presented. Some programs written by languages Gibian and special operators in Castem 2000 are established. The problem for the spherical shell made of elasto-plastic material subjected to monotone increasing pressures is solved and calculated results are compared with the theoretical solution and give a good agreement. The influence of the pressure values on the plastic regions of sphere is investigated. The stress, displacement and plastic deformation states for spherical shell and plate with hollow acted on by complex cyclic loads are considered. These given programs can be applied in other problem with more complex geometry, load and material conditions.
\end{abstract}

\section{The finite-element formulation}

The governing equation of the finite-element method for small-deformation analysis is represented as [1]:

or

$$
\int_{V}[B]^{T}\{\sigma\} d V=\int_{S}\{N\}^{T}\{T\} d s+\int_{V}\{N\}^{T}\{q\} d V
$$

$$
\int_{V}[B]^{T}\{\sigma\} d V=\{R\}
$$

where $\{T\}$ and $\{q\}$ are surface and body forces, $\{R\}$ is the equivalent external force acting on the nodal point, $[B]$ is the strain-displacement matrix and $[N]$ is the matrix of the displacement interpolation function.

In an elastic-plastic problem, the constitutive relation depends on deformation history, an incremental analysis should be used and the total load $\{R\}$ acting on a structure is added in increments step by step. To solve (1.2) for displacements $\{U\}$ corresponding to a given set of external forces the iterative methods are usually employed.

\subsection{Equilibrium iterative methods}

The load at the $(m+1)$-th step can be expressed as ${ }^{m+1}\{R\}={ }^{m}\{R\}+{ }^{m+1}\{\Delta R\}$ then equation (1.2) becomes the equilibrium of the internal force ${ }^{m+1}\{F\}$ with the external force $^{m+1}\{R\}$ :

$$
{ }^{m+1}\{F\}={ }^{m+1}\{R\},
$$


where

$$
{ }^{m+1}\{F\}=\int_{V}[B]^{T+1}\{\sigma\} d V .
$$

The equation (1.3) can be rewritten as:

$$
\psi\left({ }^{m+1}\{U\}\right)={ }^{m+1}\left\{F\left({ }^{m+1}\{U\}\right)\right\}-{ }^{m+1}\{R\}=0 .
$$

This equation can be solved on the basis of the Newton-Raphson and Quasi-Newton methods. Assuming the solution at the $(i-1)$-th approximation ${ }^{m+1}\{U\}^{i-1}$ is known, expanding $\psi\left({ }^{m+1}\{U\}\right)$ into Taylor series at ${ }^{m+1}\{U\}^{i-1}$ and neglecting all high-oder terms, we received $[1]$ :

$$
{ }^{m+1}[K]^{(i-1)}\{\Delta U\}^{(i)}={ }^{m+1}\{R\}-{ }^{m+1}\{F\}^{(i-1)},
$$

where

$$
{ }^{m+1}\{K\}^{(i-1)}=\left.\frac{\partial F}{\partial U}\right|_{m+1\{U\}^{(i-1)}}=\left.\int_{V}[B]^{T}\left[C^{e p}\right]\right|_{m+1\{U\}^{(i-1)}}[B] d V
$$

is the tangent stiffness matrix.

Assuming the solution at the $(i-1)$-th approximation ${ }^{m+1}\{U\}^{i-1}$ is known, the displacement at $i$-th iteration will be:

$$
{ }^{m+1}\{U\}^{(i)}={ }^{m+1}\{U\}^{(i-1)}+\{\Delta U\}^{(i)},
$$

where $\{\Delta U\}^{(i)}$ is defined from equation (1.5):

$$
\{\Delta U\}^{(i)}=-\left[{ }^{m+1}[K]^{(i-1)}\right]^{-1}\{\psi\}^{(i-1)} .
$$

The force quantity $\{\psi\}^{i}$ caculated at the $i$-iteration can be interpreted as an unbalanced residual force. The iteration continues until convergence criterion for example $\left\|\psi^{i}\right\| \leq \varepsilon$ is satisfied.

Note that ${ }^{m+1}\{K\}^{(i-1)}$ is evaluated and factorized at each iteration step and therefore one ussually uses the Quasi-Newton method, it employs a lower-rank matrix and the initial stiffness matrix of the structure can be used for all incremental steps [1]:

$$
{ }^{m+1}\left[K^{-1}\right]^{(i-1)}=[A]^{(i-1) T} \cdots[A]^{(1) T}{ }^{n}\left[K^{-1}\right][A]^{(1)} \cdots[A]^{(i-1)},
$$

where

$$
\begin{aligned}
& {[A]^{(i-1)}=[I]+\{V\}^{(i-1)}\{W\}^{(i-1) T}, \quad[I] \text { is a unit matrix, }} \\
& \{V\}^{(i)}=\{R\}^{(i)}-\left(1+c^{(i)}\right)\{R\}^{(i-1)}, \quad c^{(i)}=\frac{G(0)-G(1)}{G(0)}, \quad\{W\}^{(i)}=\frac{\{\Delta U\}^{(i)}}{G(0)-G(1)},
\end{aligned}
$$

and

$$
G(x)=\{\Delta U\}^{i T}\left[{ }^{m+1}\{R\}-{ }^{m+1}\left\{F\left(^{m+1}\{U\}^{(i-1)}+x\{\Delta U\}^{i}\right)\right\}\right] .
$$

At the present time, it is a best algorithm available. 


\subsection{Numerical implementation of the elastic-plastic incremental constitutive relation}

The strain-stress relations for an elastic-perfectly plastic material are expressed as [1]:

or

$$
d \varepsilon_{i j}=D_{i j k l} d \sigma_{k l}+d \lambda \frac{\partial f}{\partial \sigma_{i j}},
$$

$$
d \varepsilon_{i j}=d \varepsilon_{i j}^{e}+d \varepsilon_{i j}^{p},
$$

where $d \varepsilon_{i j}^{e}=D_{i j k l} d \sigma_{k l}$ is an elastic strain increment, and $d \varepsilon_{i j}^{p}=d \lambda\left(\partial f / \partial \sigma_{i j}\right)$ is a plastic strain increment, which is obtained from the flow rule $f, d \lambda$ is a positive scalar factor of proportionality, which is non zero only when plastic deformations occur. The factor $d \lambda$ is determined by substituting the incremental stress-strain relation:

$$
d \sigma_{i j}=C_{i j k l}\left(d \varepsilon_{k l}-d \varepsilon_{k l}^{p}\right)=C_{i j k l} d \varepsilon_{k l}-d \lambda C_{i j k l} \frac{\partial f}{\partial \sigma_{k l}},
$$

into consistency condition $d f=\frac{\partial f}{\partial \sigma_{i j}} d \sigma_{i j}=0$, so we have [1]:

$$
d \lambda=\frac{\frac{\partial f}{\partial \sigma_{i j}} C_{i j k l} d \varepsilon_{k l}}{\frac{\partial f}{\partial \sigma_{r s}} C_{r s t u} \frac{\partial f}{\partial \varepsilon_{t u}}} .
$$

Then stress increment can be determined uniquely by the yield function $f\left(\sigma_{i j}\right)$ and the strain increments $d \varepsilon_{i j}$ as:

$$
d \sigma_{i j}=C_{i j k l}^{e p} d \varepsilon_{i j}
$$

where

$$
C_{i j k l}^{e p}=\left[C_{i j k l}-\frac{C_{i j m n} \frac{\partial f}{\partial \sigma_{m n}} \frac{\partial f}{\partial \sigma_{p q}} C_{p q k l}}{\frac{\partial f}{\partial \sigma_{r s}} C_{r s t u} \frac{\partial f}{\partial \varepsilon_{t u}}}\right]
$$

represents the elastic-plastic tensor of tangent modules for an elastic-perfectly plastic material. $C_{i j k l}$ is the tensor of elastic modulus.

Thus in finite-element application, the constitutive relation of a material is reflected by this material stiffness matrix $C_{i j k l}^{e p}$, which is used in forming the tangent stiffness (1.5a) and in the relation between stress and strain increments (1.9).

\subsection{Some flow rules}

Some flow rules are used in this work:

a. Flow Rule associated with Von Mises yield function 
To take the Von Mises yield function:

$$
f\left(\sigma_{i j}\right)=J_{2}-k^{2}=0,
$$

as the plastic potential, then the flow rule has the form:

$$
d \varepsilon_{i j}^{p}=d \lambda \frac{\partial f}{\partial \sigma_{i j}}=d \lambda s_{i j},
$$

where $J_{2}=s_{i j} s_{i j} / 2, s_{i j}$ is the deviatoric stress tensor $s_{i j}=\sigma_{i j}-p \delta_{i j}, p=\sigma_{k k} / 3, k$ is the elastic yield stress in pure shear, $k=\sigma_{0} / \sqrt{3}, \sigma_{0}$ is the yield stress in simple tension and

$$
d \lambda\left\{\begin{array}{lllll}
=0 & \text { wherever } & J_{2}<k^{2} & \text { or } & J_{2}=k^{2}, \\
>0 & \text { wherever } & J_{2}=k^{2} & \text { and } & d J_{2}=0 .
\end{array}\right.
$$

b. Flow Rule associated with Tresca yield function

The yield function or plastic potential function has the form:

$$
f=\sigma_{1}-\sigma_{3}-2 k=0,
$$

where $k=\sigma_{0} / 2$. According to the associated flow rule, the pricipal plastic strain increments satisfy the following relation:

$$
\left(d \varepsilon_{1}^{p}, d \varepsilon_{2}^{p}, d \varepsilon_{3}^{p}\right)=d \lambda(1,0,-1), \quad d \lambda \geq 0 .
$$

These flow rules are used in numerical examples in this work.

\subsection{The algorithm of resolution for mechanical elasto-plasticity problems}

- Initial displacement and load increments are given:

$$
\Delta U^{(0)}=0, \quad \psi^{(0)}=\Delta R .
$$

- For each iteration step i, the displacement, strain increments and the stress state are calculated:

$$
\begin{aligned}
& \Delta U^{(i)}=K_{1}^{-1} \cdot \psi^{(i-1)} \text { from (1.6), } \\
& U^{(i)}=U^{(i-1)}+\Delta U^{(i)}, \\
& \Delta \varepsilon^{(i)}=B \cdot \Delta U^{(i)} .
\end{aligned}
$$

For a given strain increment $\Delta \varepsilon^{(i)}$, before calculating the corresponding stress increment $\Delta \sigma_{2}^{(i)}$ one must check first whether the material is in a plastic loading state corresponding to the given strain increment $\Delta \varepsilon^{(i)}$ or not.

- If $f$ is a constitutive rule (for example (1.10) or (1.11)) and $f\left(\left\{\sigma_{1}\right\}\right)<0\left(\sigma_{1}\right.$ is stress state reached on the previous load step) the process is elastic and $\Delta \sigma_{2}^{(i)}=C_{i j k l} \Delta \varepsilon^{(i)}$. If 
$f\left(\left\{\sigma_{1}\right\}\right) \geq 0$ the corresponding elastoplastic stress increment is computed by expression $\Delta \sigma_{2}^{(i)}=C_{i j k l}^{e p} \Delta \varepsilon^{(i)}$.

- The stress corresponding to $U^{(i)}$ is calculated as: $\sigma_{2}^{(i)}=\sigma_{1}+\Delta \sigma_{2}^{(i)}$.

- Calculate the equivalent force of stress acting on the nodal points $F_{2}$ and unbalanced force residual $\psi$ :

$$
\begin{aligned}
& F_{2}^{(i)}=\int_{\Omega} B^{T} \sigma_{2}^{(i)} d \Omega, \\
& \psi^{(i)}=R^{(i)}+\Delta R-F_{2}^{(i)} . \\
& \text { If }\left\|\psi^{(i)}\right\|<\varepsilon \Rightarrow \text { stop } \\
& \left\|\psi^{(i)}\right\| \geq \varepsilon \text { then } \\
& i=i+1 .
\end{aligned}
$$

The algorithm in Castem 2000 is based on the mentioned above methods [2]. As illustrations for this algorithm, some programs are written by languages Gibian, using special operators in Castem 2000 to solve elasto-plastic problems for the sphere and the plate with hollow subjected to different loads. The calculating results are presented in the next part.

\section{Numerical analysis for elasto-plastic sphere and plate with hollow subjected to different loads}

\subsection{The spherical shell with increasing pressure}

Consider the problem of finding radial displacement field of thick-walled spherical shell. The internal and external radii of the sphere are $0.01 \mathrm{~m}$ and, $0.02 \mathrm{~m}$ respectively. The sphere is made of Tresca elastoplastic material with following characteristics $E=2 \cdot 10^{5} \mathrm{MPa}$, $\nu=0.3$ and limit elastic is $Y=300 \mathrm{MPa}$. The pression is distributed uniformly over the inner surface. This pression $\mathrm{p}$ is a function of time and varies from $100 \mathrm{MPa}$ at the moment $t=0 \mathrm{~s}$ to $358.9 \mathrm{MPa}$ at $t=1000 \mathrm{~s}$. This varying of pression conducts the perfectly elasto-plastic behaviour at $R=0.015 \mathrm{~m}$.

a. The analytical solution

As the pressure is increased from zero the shell is first stressed elastically. The elastic Lamé solution for radial displacement is [4]:

$$
u=\frac{\frac{p}{E}\left\{(1-2 \nu) r+\frac{(1+\nu) b_{0}^{3}}{2 r^{2}}\right\}}{\left(\frac{b_{0}^{3}}{a_{0}^{3}}-1\right)},
$$

where $a_{0}$ and $b_{0}$ are the initial values of the radii.

With increasing pressure a plastic region spreads into the shell. The plastic boundary is spherical surface of radius $c$. The displacement then is:

$$
u\left(a_{0}\right)=\frac{Y a_{0}}{E}\left[(1-\nu) \frac{c^{3}}{a_{0}^{3}}-\frac{2}{3}(1-2 \nu)\left(1-\frac{c^{3}}{b_{0}^{3}}\right)-2(1-2 \nu) \ln \left(\frac{c}{a_{0}}\right)\right] .
$$


The radius $c$ can be defined from equation

$$
p=2 Y \ln \left(\frac{c}{a}\right)+\frac{2 Y}{3}\left(1-\frac{c^{3}}{b_{0}^{3}}\right) .
$$

b. The numerical results in comparing with analytical solutions

The numerical model for $1 / 4$ above mentioned sphere uses 224 quadratic elements and 255 nodes (Fig. 1). The symmetry conditions of the sphere lead to displacements at the boundary radii $L_{1}: U Z=0, L_{2}: U R=0$. The calculation has been realized with program written by languages Gibian, using operators of Castem 2000. The given values of radial displacement UR of the sphere at point $A\left(1 \cdot 10^{-2}, 0\right)$ are compared with analytical solution (2.1) at the moment $t=0 \mathrm{~s}$ and the solution (2.2) at the moment $t=1000 \mathrm{~s}$ in the following table.

Table 1

\begin{tabular}{|c|c|c|c|}
\hline $\begin{array}{c}\text { At the moment } \\
(\mathrm{s})\end{array}$ & $\begin{array}{c}\text { The calculated } \\
\text { UR (Micron.) }\end{array}$ & $\begin{array}{c}\text { the analytical UR } \\
\text { (Micron.) }\end{array}$ & Error \% \\
\hline$t=0$ & 3.9821 & 4 & 0.44712 \\
\hline$t=1000$ & 27.403 & 28.3 & 3.1706 \\
\hline
\end{tabular}

Where micron $=10^{-6} \mathrm{~m}$ and the error is enough small, it shows a good agreement of calculated results with theoretical ones.

The maximum Tresca stress is $303 \mathrm{MPa}$ at the internal boundary of the sphere and the plastic region is showed in the Fig. 1. The deformation of the shell at the moment of maximum load is presented in the Fig. 2.

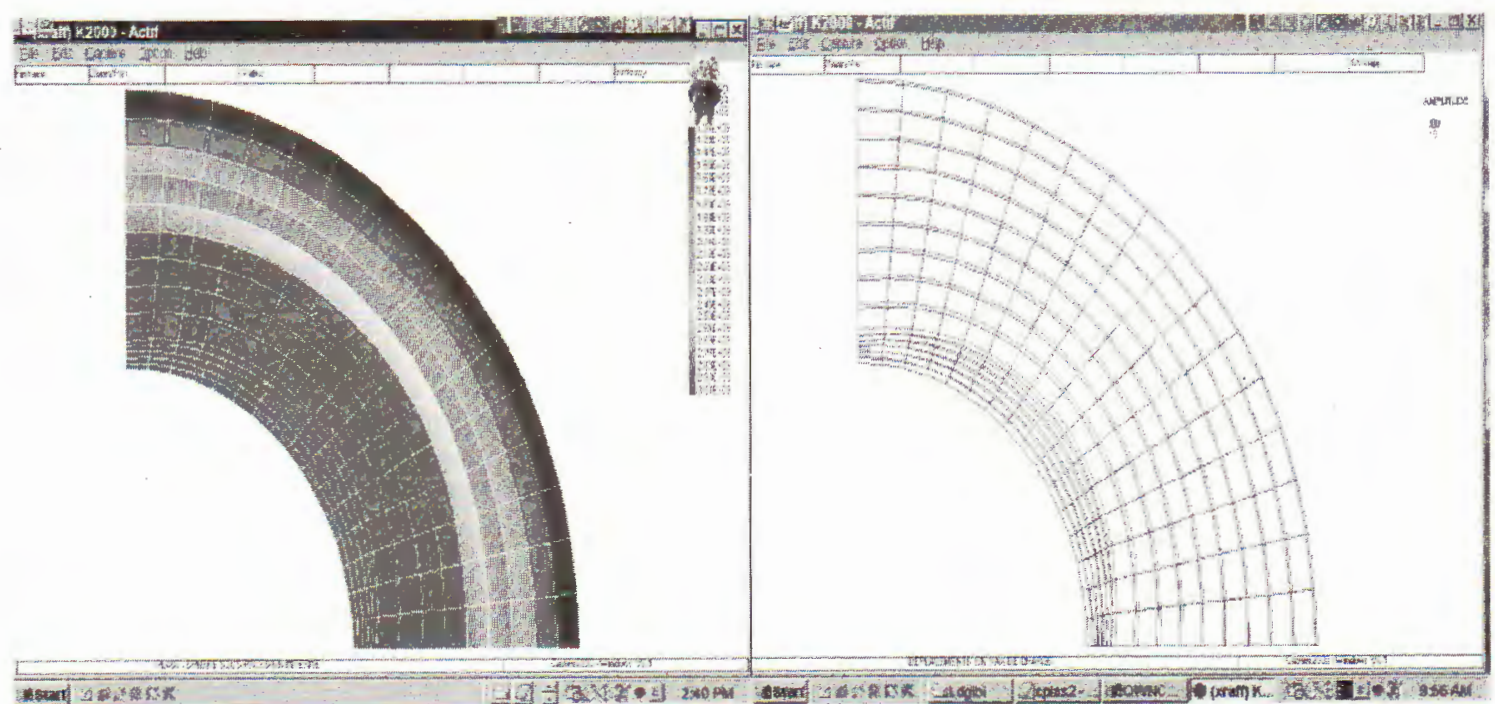

Fig. 1. The plastic region

Fig. 2. The deformation of the sphere

The shadow region $0.015 \mathrm{~m} \geq R$ is plastic.

$c$. The influence of the internal pressure changes on the displacements, maximum stresses and plasticity regions of sphere 
Consider the cases, when internal pression is function of time and increases from $p=$ $100 \mathrm{MPa}$ at the moments $t=0$ s to $p=150,180,200,250,400$ and $450 \mathrm{MPa}$ at the $t=1000 \mathrm{~s}$. The calculated results are given in the Table 1 with denoting: $U_{A M}, C, \varepsilon^{p}$, $\sigma_{M}$ are the radial displacement at the moment maximum load, radius of plastic region, maximum plastic deformation and maximum Tresca stress respectively.

Table 2

\begin{tabular}{|c|c|c|c|c|}
\hline$P_{\text {Max }}(\mathrm{MPa})$ & $U_{A M}($ Micron $)$ & $\sigma_{M}(\mathrm{MPa})$ & $\varepsilon^{p}$ & $\mathrm{C}(\mathrm{mm})$ \\
\hline 150 & 5.9732 & 250 & - & - \\
\hline 180 & 7.1678 & 300 & $1.45 \times 10^{-7}$ & 10.2 \\
\hline 200 & 8.0825 & 300 & $2.58 \times 10^{-4}$ & 10.4 \\
\hline 250 & 11.218 & 305 & $1.07 \times 10^{-3}$ & 11.5 \\
\hline 389.5 & 27.403 & 303 & $4.04 \times 10^{-3}$ & 15 \\
\hline 400 & 44.299 & 303 & $8.12 \times 10^{-3}$ & .17 \\
\hline 420 & 69.277 & 305 & $1.31 \times 10^{-2}$ & 20 \\
\hline
\end{tabular}

The Table 2 shows that when $p \geq 180 \mathrm{MPa}$ in the shell the plastic region appears and whole shell is in plastic state when $p \approx 420 \mathrm{MPa}$.

\subsection{Response of a spherical shell subjected to a cyclic loading}

Consider the sphere with the same characteristics but the pressure changes as a cyclic function: the pressure increases monotonically from $100 \mathrm{MPa}(t=0 \mathrm{~s})$ to $358.9 \mathrm{MPa}$ at the moment $t=1000 \mathrm{~s}$ and after that decreases to $100 \mathrm{MPa}(t=2000 \mathrm{~s})$ and this process repeats until $t=4000 \mathrm{~s}$.

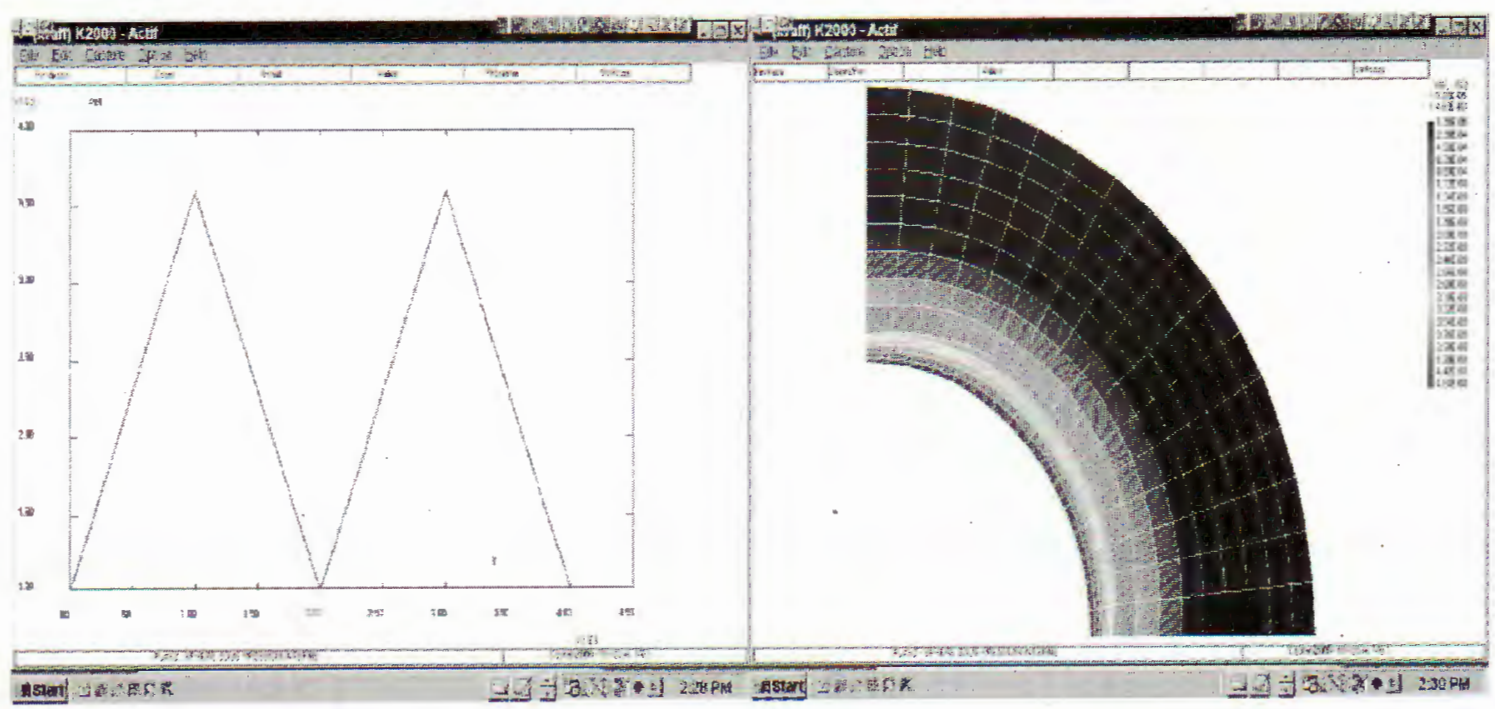

Fig. 3. Variation of force with time

Fig. 4. The plastic deformation $\varepsilon^{p}$

The time interval $[0,4000]$ is discretized in subinterval $t_{i}=250 \mathrm{~s}$ (Fig. 3 ), we can receive 
responses of the sphere at each interval ( $i$-step). The Table 3 shows some corresponding results:

Table 3

\begin{tabular}{|c|c|c|c|c|c|c|c|c|}
\hline Moment $t_{i}$ & 2 & 4 & 6 & 8 & 10 & 12 & 14 & 16 \\
\hline$\sigma_{M} \times 10^{8}(\mathrm{MPa})$ & 3 & 3.01 & 2.34 & 1.68 & 2.34 & 3.01 & 2.34 & 1.68 \\
\hline Max $\varepsilon^{p} \times 10^{-3}$ & 0.705 & 4.64 & 4.64 & 4.64 & 4.64 & 4.64 & 4.64 & 4.64 \\
\hline$U_{A M}$ (Micron) & 9.79 & 27.407 & 22.254 & 17.099 & 22.254 & 22.409 & 22.256 & 17.1 \\
\hline
\end{tabular}

Note that the given stress and displacement results are changed as cyclic loading. In the Fig. 4 the maximum plastic deformation reaches at the boundary region, where $12 \mathrm{~mm}$ $\geq R \geq 10 \mathrm{~mm}$ and it is constant at all steps $i \geq 2$.

\subsection{Response of a plate with hollow subjected to a sinusoidal loading}

Consider a quarter of rectangular plate. Its width and length are: $a=30 \mathrm{~mm}, b=$ $100 \mathrm{~mm}$ (Fig. 5), the radius of circular hollow is $r=10 \mathrm{~mm}$. The plate is subjected to a cyclic sinusoidal loading (Fig. 6) on the line $L_{67}$. On the $L_{13}: U_{y}=0, L_{24}: U_{x}=0$ which satisfy symmetry geometrical condition. On the $L_{45}$ the displacement values are given and equal to $0.06 \mathrm{~mm}$. The plate is made of Von-Mises elastoplastic material with following characteristics $E=2.10^{5} \mathrm{MPa}, \nu=0.3$ and limit elastic is $Y=300 \mathrm{MPa}$.

The model consists of 486 elements and 270 nodes. The mesh is divided as in the Fig. 5, the place near to hollow has smallest mesh density.

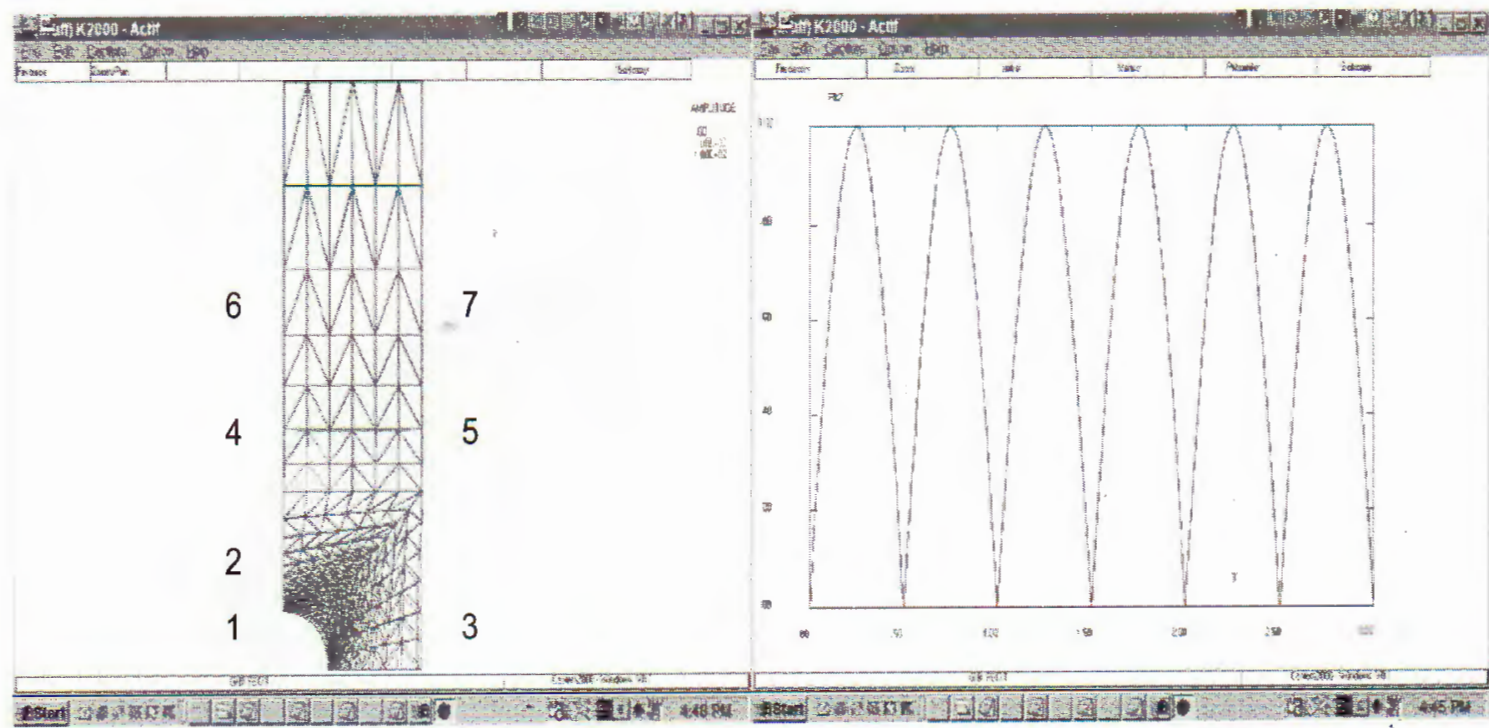

Fig. 5. The deformation of plate

Fig. 6. Cyclic sinusoidal load

The numerical results let us to know the stress, displacement and deformation states (Fig. 5). The diagram of various deformations and stresses, depending on the time are represented in the Fig. 7 and Fig. 8 , the plasticity region in the Fig. 9 and the relation of deformation and stresses in the Fig. 10. 


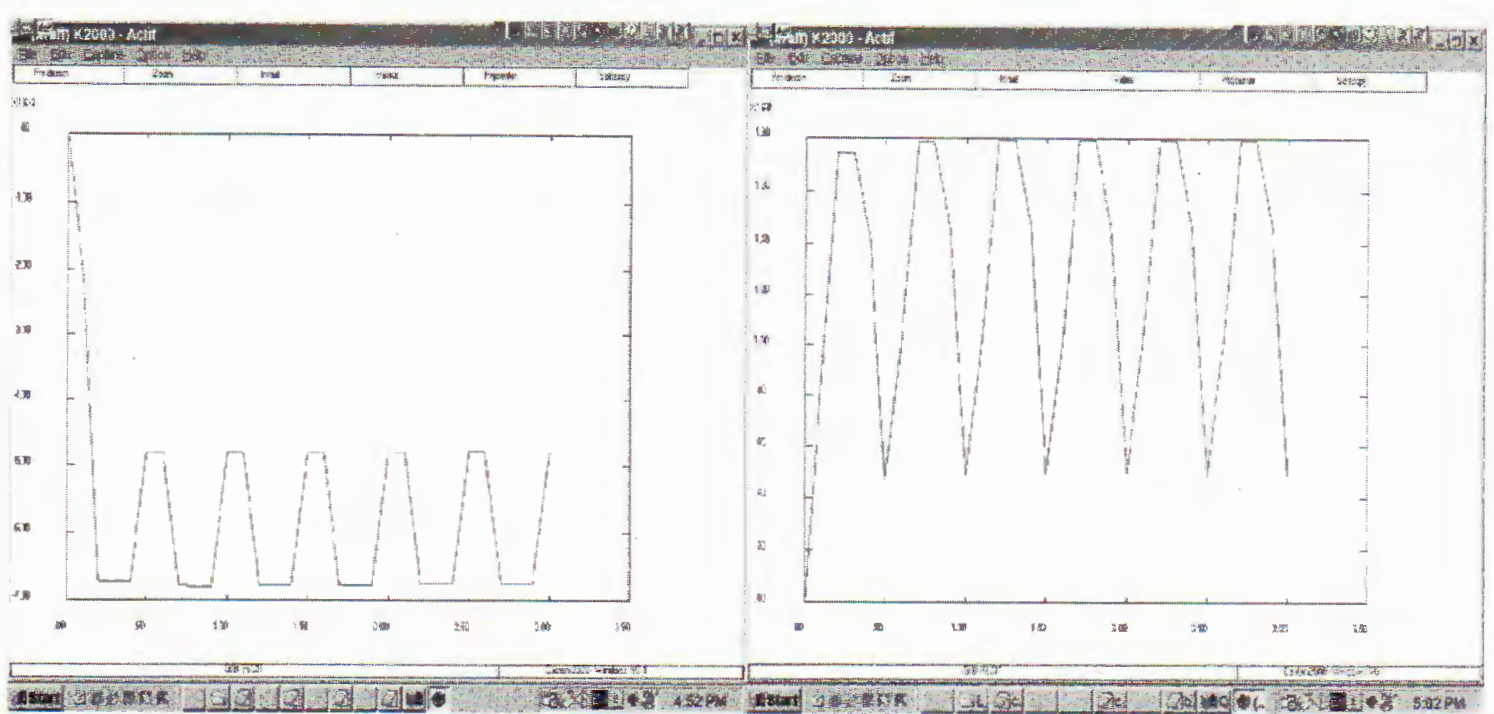

Fig. 7. Variation of deformations with time

Fig. 8. Variation of stresses with time

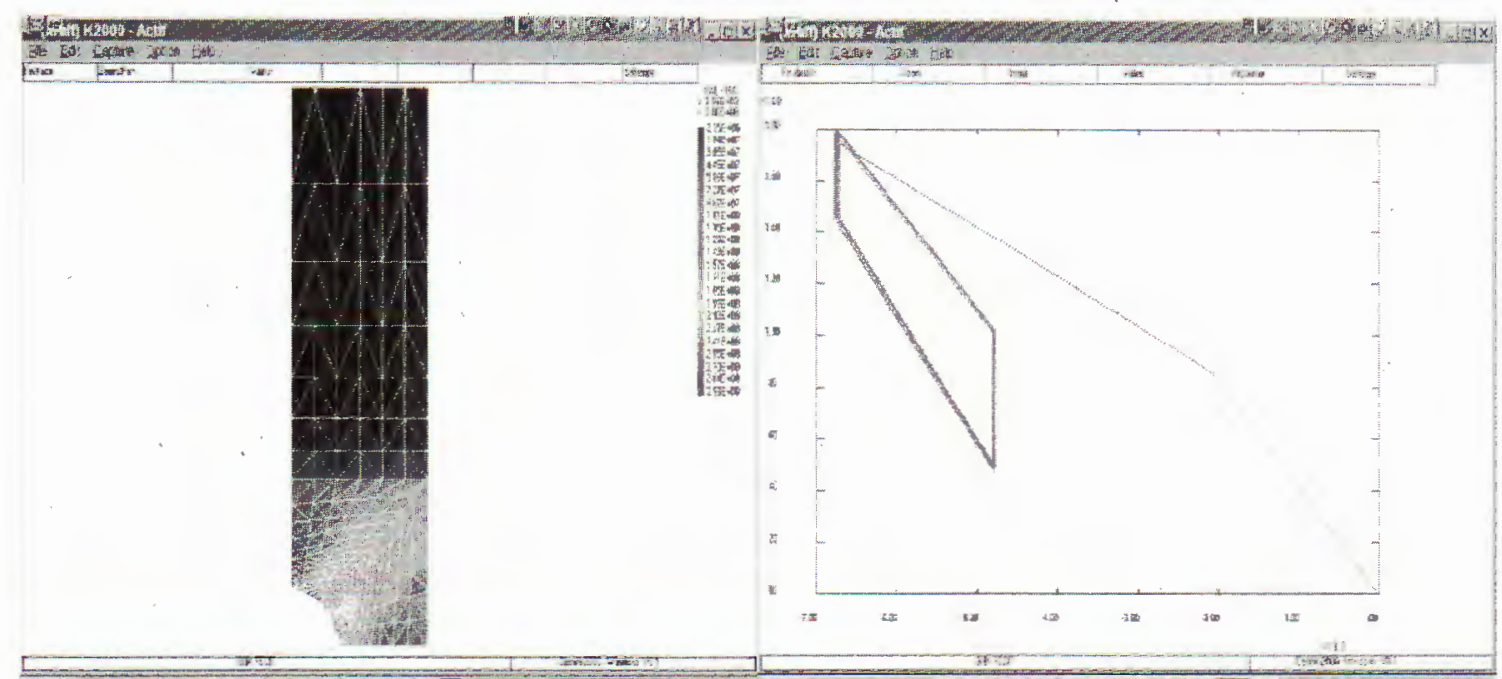

Fig. 9.The plasticity region

Fig. 10. Relation of inelastic deformations and stresses

The Fig. 10 shows that after a certain number of cycles, the response of the structure becomes periodic. This implies that $\varepsilon^{p}$ tend toward periodical fields and the structure reacheases plastic shakedown [5].

\section{Conclusion}

In this work some elasto-plastic constitutive problems for sphere and plate under monotone increasing pressures and cyclic loading are solved. In the simple case, the solution is verified 
with theoretical solution and given errors are enough small. The calculated program results show that the algorithm and corresponding program written by languages Gibian and the special operators in Castem 2000 can give the displacement, stress and plastic deformation states of the structures in the more complex cases.

This work is completed with financial support of the Council for Natural Science of Vietnam.

\section{References}

1. Chen W. F. and Han D. J., Plasticity in Structural Engineering, Springer-Verlag, 1988 .

2. Alain Millard, Pierre Verpeaux, Thierry Charras., Castem 2000: Pourquoi et Comment, Proccedings Inter. Conf. EMT' 97. V. Z. P. 376-386.

3. C. E. A/D. M. T/L. A. M. S., Castem 2000 Recueil D'exemples Commentes, 1992.

4. Hill R., The Mathematical Theory of Plasticity, Oxford, 1964.

5. Zarka J., Inglebert G. and Kasmai-Navidi P., A New Approach in Inelastic Analysis of Structures, Laboratoire de Mecanique des Solides, Ecole Polytechnique, France, 2000 .

Received August 8, 2003

\section{PHÂN TÍCH SỐ MỘT SỐ BÀI TOÁN CÓ ÚNG XƯ PHI TUYẾN TRONG CO HOC VÂT RẮN}

Bài báo đề cập đến ứng dụng phương pháp phần tử hữu hạn trong việc giải số các bài toán vật rắn có luật ứng xư phi tuyến. Các phương trình cơ bàn và thuật toán của qúa trình lặp đã được trình bầy. Một số chương trình đã được thiết lập bằng ngôn ngữ Gibian và các toán tử của phần mềm Castem 2000 để giải các bài toán bản vó. Bài toán đàn déo cho vỏ cầu chịu áp trong tăng dần đã được giải số và so sánh phù hợp với nghiệm giải tích. Ảnh hưởng của áp lực đến bán kính vùng dèo cũng được nghiên cứu. Trường ứng suất biến dạng, biến dạng dẻo của vỏ cầu và bản có lỗ khoét chịu tải trọng lặp theo chu trình cũng đã được tính toán. Các chương trình nhận được có thể tính cho nhiều trường hợp hình học, tải và vật liệu phức tạp khác. 